Int. J. Electrochem. Sci., 15 (2020) 10885 - 10907

International Journal of

ELECTROCHEMICAL

SCIENCE

WWW.electrochemsci.org

\title{
Potentiometric Study, DFT Calculations and Thermodynamic Parameters of Complex Formation between $\mathrm{Cd}(\mathrm{II})$ and Thiosemicarbazone Ligand
}

\author{
Ahmed A. El-Sherif ${ }^{1, *}$, Abeer A. El-Sisi ${ }^{2}$, Mohamed Ali ${ }^{1}$, Sohair F. Ramdan ${ }^{3}$, Osama AlTaweel ${ }^{4}$, \\ Abeer T. AbdEl-Karim ${ }^{1}$ \\ ${ }^{1}$ Department of Chemistry, Faculty of Science, Cairo University, Cairo, Egypt. \\ ${ }^{2}$ Forensic medicine authority, Ministry of Justice, Egypt \\ ${ }^{3}$ Department of Zoology, Faculty of Science, Cairo University, Cairo, Egypt. \\ ${ }^{4}$ Department of Forensic medicine, Cairo University, Faculty of Veterinary, \\ *E-mail: aelsherif72@yahoo.com
}

doi: $10.20964 / 2020.11 .11$

Received: 23 April 2020 / Accepted: 22 August 2020 / Published: 30 September 2020

(E)-N-methyl-2-((E)-1-(2-(p-tolyl)hydrazono)propan-2-ylidene)hydrazine-1-carbothioamide

(MTHPH) has been synthesized and characterized using elemental analyses, IR, mass spectra and ${ }^{1} \mathrm{H}-$ NMR measurements. The antibacterial, antifungal and antioxidant activity studies of the synthesized MTHPH ligand was investigated and discussed. Molecular modeling was drawn for MTHPH thiosemicarbazone compound and its molecular parameters were determined. Novel MTHPH ligand protonation constants and its formation constants with $\mathrm{Cd}(\mathrm{II})$ ion were determined in 50\% DMSO solution at $15{ }^{\circ} \mathrm{C}, 25{ }^{\circ} \mathrm{C}$ and $35{ }^{\circ} \mathrm{C}$. The solution speciation of different species was measured as a function of $\mathrm{pH}$. Calculation and discussion of the thermodynamic parameters were accomplished. Both $\log \mathrm{K}_{1}$ and $-\Delta \mathrm{H}_{1}$, for $\mathrm{Cd}(\mathrm{II})$-complexes have been observed to some degree greater than $\log \mathrm{K}_{2}$ and $\Delta \mathrm{H}_{2}$, indicating a change in the dentate character of this ligand from tridentate donors in $1: 1$ chelates to bidentate in 1:2; M:L chelates in addition to steric hindrance induced by entry of $2^{\text {nd }}$ molecule. MTHPH compound may be considered as a good remedy for $\mathrm{Cd}^{2+}$ toxicity.

Keywords: Potentiometry; Schiff base; thermodynamics, speciation, Mass spectra, Cadmium.

\section{$\underline{\text { FULL TEXT }}$}

(C) 2020 The Authors. Published by ESG (www.electrochemsci.org). This article is an open access article distributed under the terms and conditions of the Creative Commons Attribution license (http://creativecommons.org/licenses/by/4.0/). 